\title{
Corrosion Resistance of Mild Steel in Hydrochloric Acid Solutions by Clinopodium acinos as a Green Inhibitor
}

\author{
Abd El-Aziz S. Fouda 1,* (D), El-Sayed El-Gharkawy ${ }^{1}$, Heba Ramadan ${ }^{1}$, Ahmed El-Hossiany ${ }^{1,2}$ \\ 1 Department of Chemistry, Faculty of Science, El-Mansoura University, Egypt \\ 2 Delta Fertilizers Company on Talkha, Egypt \\ * Correspondence: asfouda@ hotmail.com;
}

Scopus Author ID 56231506400

Received: 20.06.2020; Revised: 5.09.2020; Accepted: 7.09.2020; Published: 16.09.2020

\begin{abstract}
Study of corrosion inhibition for mild steel in $1 \mathrm{M} \mathrm{HCl}$ by Clinopodium acinos (CA) extract was evaluated by altered methods. These methods are WL, electrochemical tests (Electrochemical frequency modulation (EFM), potentiodynamic polarization (PP), and electrochemical impedance spectroscopy (EIS)) and surface examination performances (AFM, ATR- FTIR and XPS). The CA extract concentrations are $(50,100,150,200,250,300 \mathrm{ppm})$ at altered temperatures $25,30,35,40,45$ ${ }^{0} \mathrm{C}$.WL curves showed raising the inhibition efficiency of M-S by increasing CA concentration and lowering the temperature. PP curves explained that CA extract act as a mixed type inhibitor. The green inhibitor was utilized because of its lower price and not affect the environment.
\end{abstract}

Keywords: M-S; CA; Corrosion inhibition; HCl; WL; PP; EIS; EFM; AFM; ATR-FTIR; XPS.

(C) 2020 by the authors. This article is an open-access article distributed under the terms and conditions of the Creative Commons Attribution (CC BY) license (https://creativecommons.org/licenses/by/4.0/).

\section{Introduction}

Metal corrosion occurs as a result of oxidation-reduction reactions found in the environment surrounding the metal [1]. MS is one of the metals used in industrial applications. It is used for handling of alkaline, acids, and salt solutions [2]. Acidic solutions are the most commonly used in the industrial process as like pickling, cleaning, descaling [3]. Various types of inhibitors are utilized to protect the corrosion of MS in acidic solutions. Nowadays a plant extracts (a green inhibitor) are the most utilized due to it is not expensive and not damage the environment [4]. The molecules of the inhibitor were adsorbed on the metal surface and block the active site due to prevent anodic and cathodic reactions [5].

In this study, CA extracts were utilized to inhibit the corrosion of MS in $1 \mathrm{M} \mathrm{HCl}$. Many altered tests are utilized to study the protection efficiency of CA. In WL and electrochemical tests, the corrosion rate rises with the increase of the CA extract concentration. The surface of the metal is premeditated by AFM, ATR-FTIR, XPS.

\section{Materials and Methods}

\subsection{Composition of $M-S$ sample.}

The chemical elements present in the $\mathrm{S}$ sample recorded in Table (1):

\begin{tabular}{l|c|c|c|c|c|c|c|c} 
Table 1. The wt. \% of M-S coins were given. \\
wt\% & $\mathbf{C}$ & $\mathbf{S i}$ & $\mathbf{M n}$ & $\mathbf{S}$ & $\mathbf{C u}$ & $\mathbf{P}$ & $\mathbf{N i}$ & $\mathbf{F e}$ \\
\hline $\mathrm{M}-\mathrm{S}$ & 0.17 & 0.24 & $0.7-0.9$ & 0.04 & 0.036 & 0.006 & 0.025 & the rest
\end{tabular}




\subsection{Chemicals.}

\subsubsection{Inhibitor.}

The leaves of "CA were collected and dried at room temperature then ground to a fine powder using an electrical mill. $(200 \mathrm{~g})$ of this powder soaked in $800 \mathrm{ml}$ methanol, and then the methanolic extract of the sample was concentrated to near dryness under vacuum by using the rotary evaporator at $45^{\circ} \mathrm{C}$ and got a stock of methanolic extract. The investigated extract was liquefied in ethanol $(1 \mathrm{~g} / \mathrm{L})$ and conserve into the refrigerator. We use the solution $(1000 \mathrm{ppm})$ to prepare different concentrations of CA extract (50,100,150,200,250,300 ppm)" [6].

Known commonly as basil thyme and spring savory, is a species of plant of the genus Acinos. It is a perennial that usually grows about 8 inches $(20 \mathrm{~cm})$ high and spreads 12 inches $(30 \mathrm{~cm})$. It prefers to grow in strong sunlight. Acinos arvensis is recorded as a food plant for the larva of the moth Coleophora tricolor. This plant is classified by Rose (The Wildflower Key, revised 2006) as Clinopodium acinos (Scheme 1).

Botanical Name : Clinopodium acinos

Family : Lamiaceae

Part used : Leaves and flowers

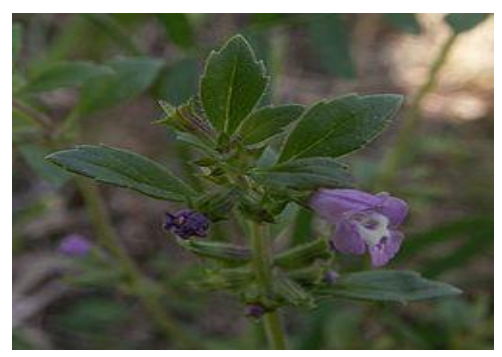

Scheme 1. The plant used in this paper and its family.

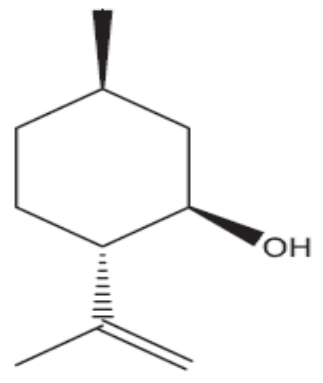

Isopulegol

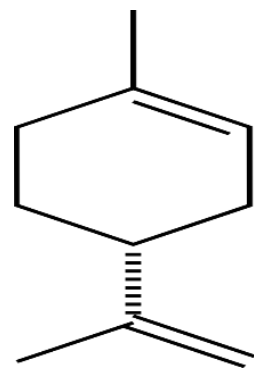

Limonene

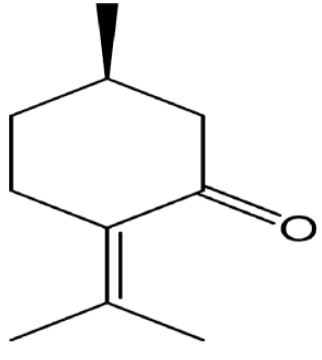

Pulegone

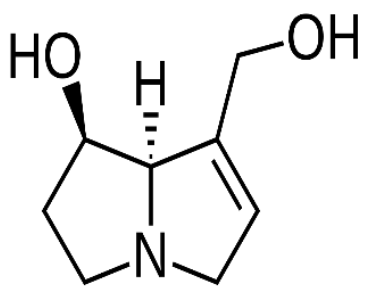

Retronecine

Scheme 2. Main components in the used plant.

\subsubsection{Solutions.}

A corrosive solution of $1 \mathrm{M} \mathrm{HCl}$ was prepared to utilize double distilled water and standardized with $\mathrm{Na}_{2} \mathrm{CO}_{3}$. $\mathrm{HCl}$ solution prepared from a stock of $\mathrm{HCl} 37 \%$ (purchased from El-Nasr, Egypt) with water demineralized. The concentration of the extract used was $(50,100,150,200,250,300 \mathrm{ppm})$.

\subsection{Techniques utilized for calculation of inhibition efficiency.}

\subsubsection{Weight loss technique (WL).}

WL technique is a simple technique, which applied to calculate the inhibition efficiency of CA extract on MS in 1M HCl [7]. "Square pieces of C-S with size (2 cm x $2 \mathrm{~cm} \mathrm{x} 0.2 \mathrm{~cm}$ ) were used in this method. The MS pieces were prepared by using emery papers with a degree $(600,1000,1200,2000)$ then we use acetone to remove impurities from the surface. Inhibition of C-S corrosion was investigated under different temperatures $(25,30,35,40,45)$ and various 
concentrations of CA extract solution (50,100, 150,200,250,300 ppm). From this method, we can calculate corrosion rate $(\mathrm{CR})$, surface coverage area $(\theta)$, and inhibition efficiency $(\%$ IE)" as the next Eq. [8].

$$
\% \mathrm{IE}=\theta \times 100=\left[1-\left(\mathrm{W} / \mathrm{W}^{\circ}\right)\right] \times 100
$$

Where, $\mathrm{W}^{\mathrm{o}}$ and $\mathrm{W}$ are the $\mathrm{MR}$, nonexistence, and existence, adding a deferent dose of investigating inhibitor continually.

\subsubsection{Electrochemical techniques.}

In Electrochemical studies, the \% IE calculated by using three methods PP, EIS, EFM. These studies were achieved by using Gammry three-electrode cell at $25^{\circ} \mathrm{C}$. "The MS act as a working electrode, platinum electrode act as an auxiliary electrode, and a saturated calomel electrode act as a reference electrode. The working electrode was polisher with papers grit 1200 in size. Before tests, the electrode was inundation in $\mathrm{HCl}$ at potential natural for half hours. Until arrived at a steady-state". All electrochemical measurements were performed utilizing a Gamry Instrument (PCI4/750) Potentiostat/ Galvanostat/ZRA.

\subsubsection{PP technique.}

In this method tafel curves obtained between $0.1-0.2 \mathrm{v}$ with $1 \mathrm{mVs}^{-1}$ scan rate. All tests were done in freshly readying solutions at $25^{\circ} \mathrm{C}$. From the outcome data we can calculate $\%$ IE and $\theta$ as below [9]

$$
\text { IE } \%=100 \times \theta=100 \times\left[1-\left(i_{\text {corr(inh })} / i_{\text {corr }(f r e e)}\right)\right]
$$

$\mathrm{i}_{\text {corr(inh) }}$ and $\mathrm{i}_{\text {corr(free) }}$ are the current for corrosion in the nonexistence and existence of extract, continually.

\subsubsection{EIS technique.}

EIS tests carried out using AC signals of $5 \mathrm{mv}$ at $\mathrm{OCP}$ in the frequency range $(0.2 \mathrm{~Hz}$ to $100 \mathrm{kHz}$ ). The diameters given of the capacitive loops improve in the existence of inhibitors and are led to the capacitive of the extent of inhibition of process corrosion, contrary to the lower of the $\mathrm{C}_{\mathrm{dl}}$, which is given as:

$$
\mathrm{C}_{\mathrm{dl}}=1 /\left(2 \pi f_{\max } \mathrm{R}_{\mathrm{p}}\right)
$$

$f_{\max }=$ frequency maximum. The IE \%and $(\theta)$ given from EIS analyses were obtained by the next relation:

$$
\mathrm{IE} \%=100 \times \theta=100 \times\left[1-\left(\mathrm{R}_{\mathrm{p}}^{\circ} / \mathrm{R}_{\mathrm{p}}\right)\right]
$$

$\mathrm{R}_{\mathrm{p}}^{\mathrm{o}}$ and $\mathrm{R}_{\mathrm{p}}$ are the charge resistance in the nonexistence and existence of extract, respectively.

\subsubsection{EFM technique.}

The study of EFM was performed by using a signal with $10 \mathrm{mV}$ amplitude with 2 single waves of 2 and $5 \mathrm{~Hz}$ [10]. The larger peaks were utilized to measure the $\left(\mathrm{CF}_{2}\right.$ and $\left.\mathrm{CF}_{3}\right)$ causality factors $\left(\beta_{\mathrm{c}}\right.$ and $\beta_{\mathrm{a}}$ ) and (icorr) [11]. The inhibition of efficiencies \% IE EFM was calculated as follows:

$$
\% \mathrm{IE}_{\mathrm{EFM}}=100 \mathrm{X}\left[1-\left(\mathrm{i}_{\text {corr. }} / \mathrm{i}^{\mathrm{o}} \text { corr. }\right)\right]
$$

Where, $\mathrm{i}^{\mathrm{o}}$ corr and $\mathrm{i}_{\text {corr }}$ are current corrosion in the nonexistence and existence of CA extract. 
2.4. Surface analysis.

2.4.1. Atomic force microscopy.

AFM spectroscopy gives a 3D image of the film formed on the metal surface. This was achieved by Thermo Fisher Nicolet IS10, USA spectral range of $400-4000 \mathrm{~cm}^{-1}$. The image appears roughness, which gives information about the inhibitor reaction.

\subsubsection{ATR-FTIR.}

(FT-IR) spectra were recorded using a Thermo Scientific Nicolet 6700 FT-IR Spectrometer (Thermo Fisher Scientific, Waltham, MA, USA). This spectrum gives a peak corresponding to the function group and explains the type of reaction.

2.4.3. X-ray photoelectron spectroscopy analysis (XPS).

The surface of MS after it engages in $1 \mathrm{M} \mathrm{HCl}$ solution in the absence and attendance of $300 \mathrm{ppm}$ CA for $24 \mathrm{~h}$ was characterized by XPS K-ALPHA (Thermo Fisher Scientific, USA).

\section{Results and Discussion}

\subsection{Weight loss (WL) tests.}

As showed in the Fig (1), the "WL-time curves " were determined in the presence and absence of various concentrations of CA extract. The values of CR, $\Theta$, and IE\% are listed in the Table (2). From the Table we noted that CR decrease with increasing of CA extract doses due to increasing of $\Theta$ by adsorption of CA extract on the MS surface. The IE\% increase with increasing of CA extract doses and by increasing of temperature" [12].

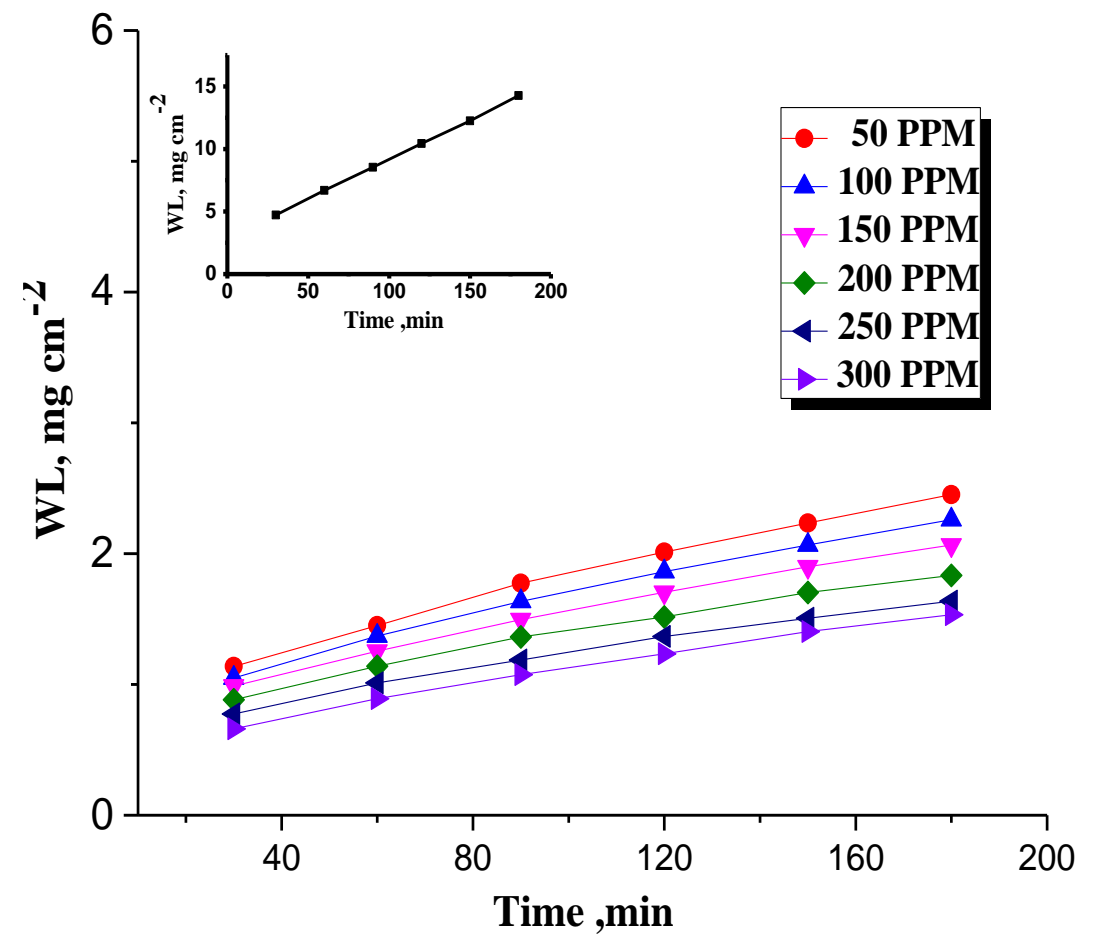

Figure 1. Curves of Weight loss vs. time for the corrosion of $\mathrm{M}-\mathrm{S}$ in $1 \mathrm{M} \mathrm{HCl}$ in the absence and presence of different doses of CA extract at $25^{\circ} \mathrm{C}$. 
Table 2. WL measurements for MS at temperatures (25-45) at $120 \mathrm{~min}$ in the presence and absence of different doses of CA extract.

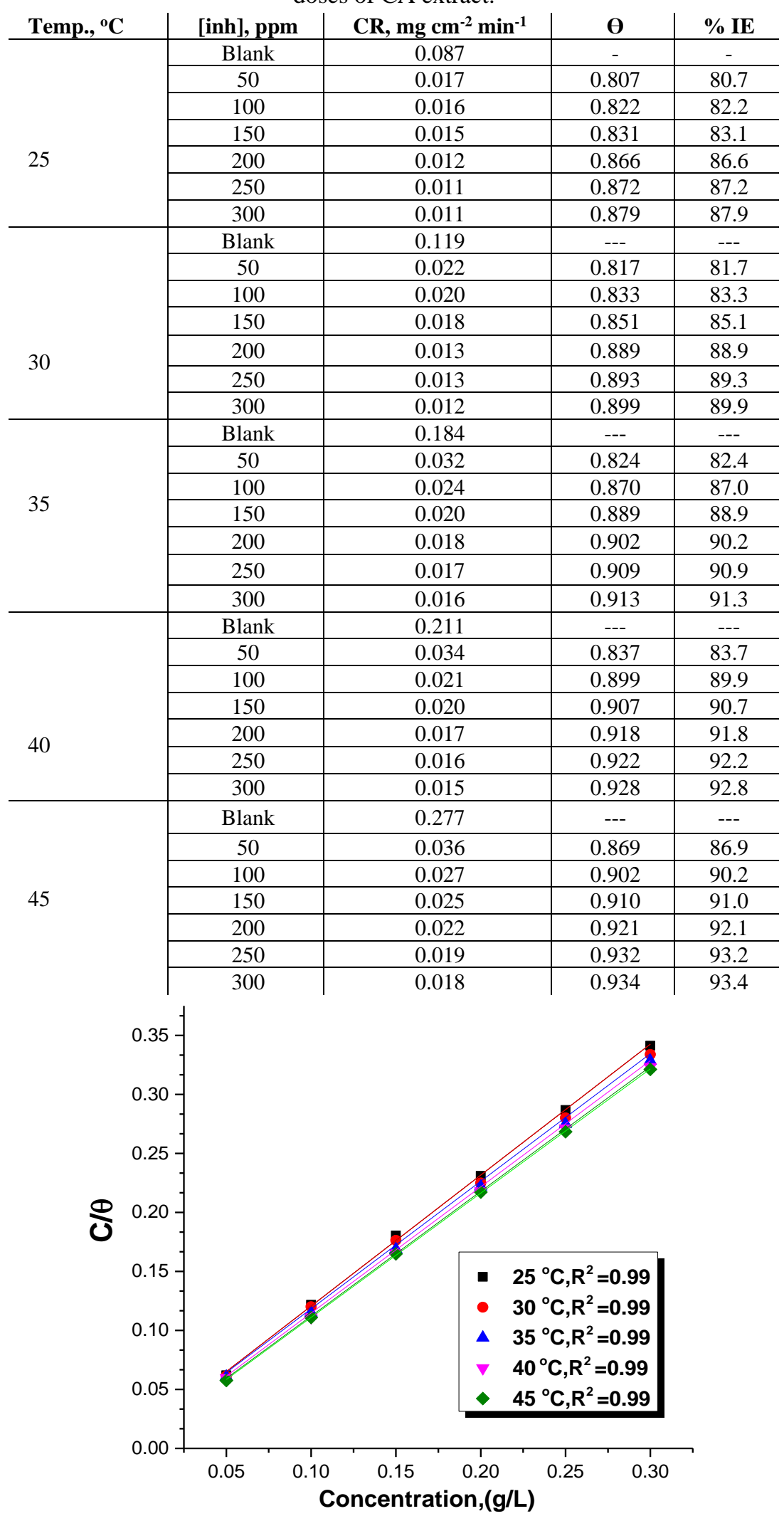

Figure 2. Plot of Langmuir adsorption of $\mathrm{M}-\mathrm{S}$ in $1 \mathrm{M} \mathrm{HCl}$ in the absence and presence of different doses of $\mathrm{CA}$ extract.

\subsubsection{Adsorption isotherms.}

The information of the interaction between CA extract and the MS surface in $1 \mathrm{M} \mathrm{HCl}$ is given by adsorption isotherms. "There are several adsorption isotherms like Langmuir, 
Temkin, Freundlich, Bockris-Swinkless, and Flory-Huggins isotherms [13]. But the Langmuir adsorption isotherm is the best fit that gives information on the interaction between the adsorbed layers of the CA extract and the surface of $\mathrm{MS}$ in $1 \mathrm{M} \mathrm{HCl}$ and is represented by (Eq. 6). The relationship is linear among (C) and $\mathrm{C} / \Theta$ given in lines straight (Fig. 2)". Kads belong to $\Delta \mathrm{G}_{\text {ads }}^{0}$ as in (Eq. 7) [14].

$$
\begin{aligned}
& \mathrm{C} / \Theta=1 / \mathrm{K}_{\text {ads }}+\mathrm{C} \\
& \Delta \mathrm{G}^{0} \mathrm{ads}=\mathrm{RT} \ln \left(\mathrm{K}_{\text {ads }} \times 55.5\right)
\end{aligned}
$$

where $\mathrm{K}_{\mathrm{ads}}=$ constant equilibrium, $\mathrm{R}=$ Universal gas constant, $\mathrm{T}=$ temperature in Kelvin and $\mathrm{C}=$ dose of CA extract.

From Vant Hoff equation:

$\mathrm{Ln} \mathrm{K}_{\mathrm{ads}}=-\Delta \mathrm{H}^{\mathrm{o}} / \mathrm{RT}+$ constant

By plotting ln Kads vs. 1/T (Fig.3), gives a straight line with slope equals to $\Delta \mathrm{H}^{\mathrm{o}}$ as seen in Table 3.

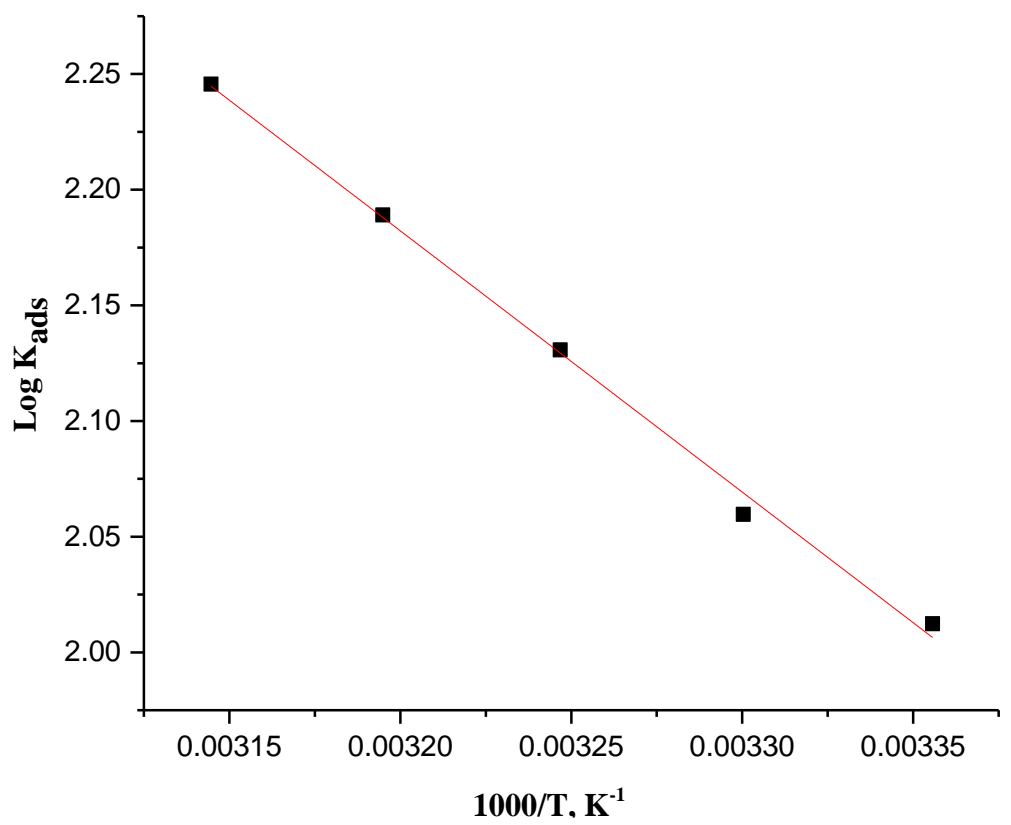

Figure 3. Plot of $\log \mathrm{K}_{\mathrm{ads}} \mathrm{vs} 1 / \mathrm{T}$ for the adsorption of CA extracts on $\mathrm{MS}$ in $1 \mathrm{M} \mathrm{HCl}$ at $\left(25-45^{0} \mathrm{C}\right)$.

\begin{tabular}{|c|c|c|c|c|c|}
\hline Compound & $\begin{array}{l}\mathbf{T}, \\
\mathbf{K}\end{array}$ & $\begin{array}{c}\text { KadsX10 } \\
\mathbf{M}^{-1}\end{array}$ & $\begin{array}{c}-\Delta \mathbf{G}_{\text {ads }}^{\circ} \\
\mathbf{k J} \text { mol }^{-1}\end{array}$ & $\begin{array}{c}-\Delta \mathbf{H}^{\circ}{ }^{a d s} \\
k \mathbf{k J ~ m o l}^{-1}\end{array}$ & $\begin{array}{c}-\Delta \mathbf{S}_{\text {ads }}^{\circ} \\
\mathbf{J ~}^{\mathbf{m o l}^{-1} \mathbf{K}^{-1}}\end{array}$ \\
\hline \multirow{5}{*}{$\mathrm{CA}$} & 298 & 103 & 21.5 & \multirow{5}{*}{21.6} & 144.6 \\
\hline & 303 & 112 & 22.0 & & 143.9 \\
\hline & 308 & 129 & 22.7 & & 144.0 \\
\hline & 313 & 154 & 23.6 & & 144.3 \\
\hline & 318 & 176 & 24.3 & & 144.4 \\
\hline
\end{tabular}

Table 3. Adsorption parameters of CA extract on MS surface by Langmuir isotherm at $\left(25-45^{\circ} \mathrm{C}\right)$.

The data listed in Table (3) indicate that: 1) $\mathrm{K}_{\text {ads }}$ values increase with an increase in temperature. 2) $\Delta \mathrm{G}^{\circ}$ ads negative sign indicates that the CA extract is adsorbed spontaneously on M-S surface [15]. 3) $\Delta \mathrm{G}_{\text {ads }}^{\mathrm{o}}$ data more than $20 \mathrm{~kJ} \mathrm{~mol}^{-1}$, which gives is a mixed type and spontaneous. 4) $\Delta \mathrm{H}^{\mathrm{o}}$ ads negative sign indicates that the adsorption of CA extract is an exothermic process. $5 . \Delta \mathrm{S}^{\circ}$ ads have a negative sign because CA molecules freely moving in the bulk solution were adsorbed in an orderly fashion on to MS, resulting in a decrease in entropy [16]. 


\subsubsection{Thermodynamic corrosion parameter.}

The activation parameters for the corrosion of $\mathrm{MS}$ in $1 \mathrm{MHCl}$ in the presence and absence of various doses of CA extract are calculated from Arrhenius and transition state equations (Eq. 9, 10)

$$
\begin{aligned}
& \mathrm{k}_{\text {corr }}=\mathrm{A} \mathrm{e}^{-\mathrm{E}^{*} \mathrm{a} / \mathrm{RT}} \\
& \mathrm{k}_{\text {corr }}=\mathrm{RT} / \mathrm{Nh} \mathrm{e}^{\left(\Delta \mathrm{S}^{*} / \mathrm{R}\right)} \mathrm{e}^{\left(-\Delta \mathrm{H}^{*} / \mathrm{RT}\right)}
\end{aligned}
$$

$\mathrm{E}^{*} \mathrm{a}_{\mathrm{a}}$ activation energy, As represented in (Figure 4) we plot $\log \mathrm{k}_{\text {corr }}$ versus $1 / \mathrm{T}$ for MS in 1 $\mathrm{M} \mathrm{HCl}$ in the presence and absence of various doses of CA extract than from the slope, the values of $\mathrm{E}_{\mathrm{a}}{ }^{*}$ were deliberate. In (Figure 5) we plot $\log \mathrm{k}_{\mathrm{corr}} / \mathrm{T}$ versus $1 / \mathrm{T}$, which gives a straight where the slope is $\Delta \mathrm{H} / 2.303 \mathrm{R}$, and the intercepts are of $\log \mathrm{R} / \mathrm{Nh}+\Delta \mathrm{S}^{*} / 2.303$ [17].

The obtained data are recorded in the (Table 4), and from it, we noted that:

1) $\mathrm{E}_{\mathrm{a}}{ }^{*}$ values in the presence of $\mathrm{CA}$ extract are higher than when $\mathrm{CA}$ is absent due to the adsorption of the CA on MS surface and formation of a barrier layer, which decreases CR. The values of $\mathrm{E}_{\mathrm{a}}^{*}$ increase with increasing of CA dose. 2) $\Delta \mathrm{S}^{*}$ negative sign indicates that the activated complex at the rate-determining step favor an association rather than a dissociation [18].

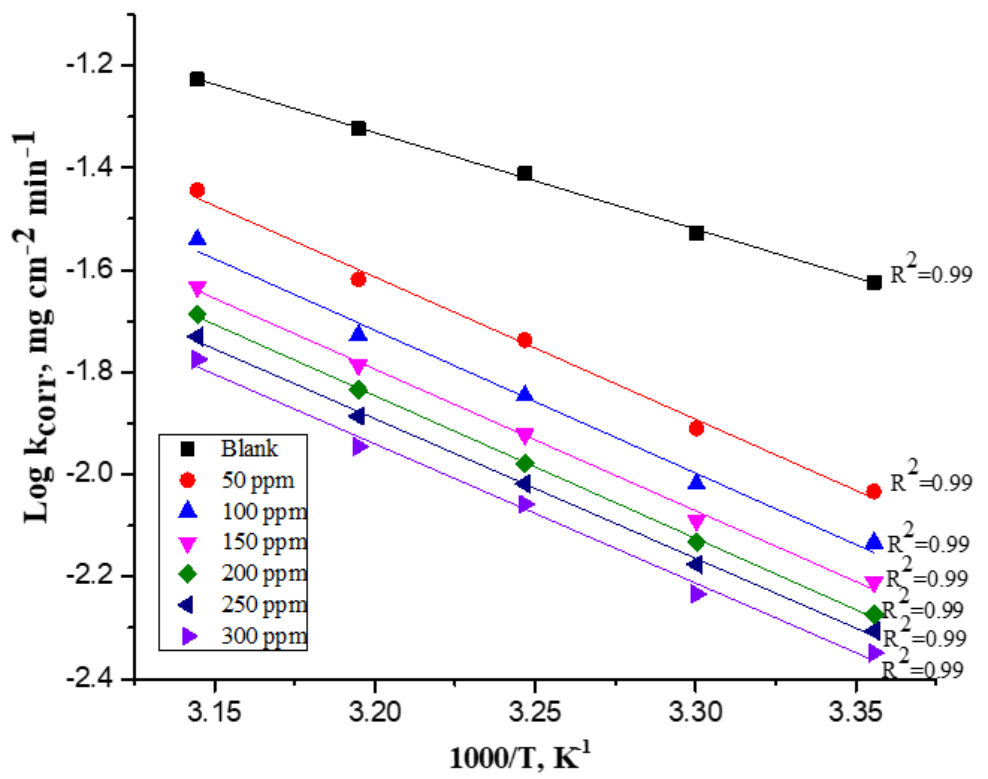

Figure 4. Plot of $\log \mathrm{k}_{\text {corr }}$ vs $1 / \mathrm{T}$ for $\mathrm{M}-\mathrm{S}$ in the presence and absence of CA extract in $1 \mathrm{M} \mathrm{HCl}$.

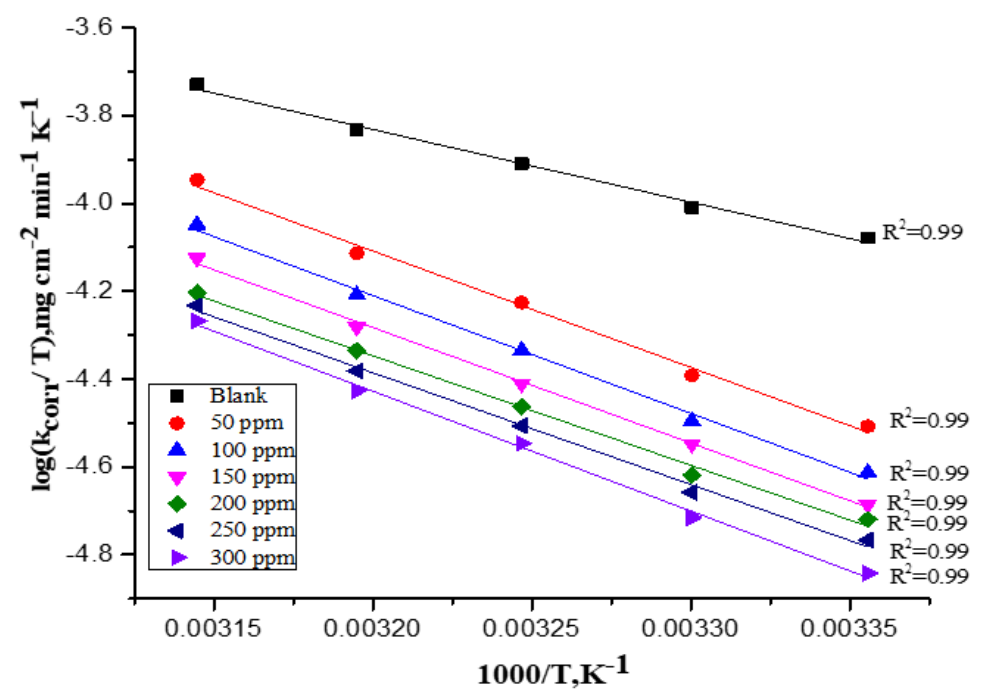

Figure 5. Plot of $\log \mathrm{k}_{\text {corr }} / \mathrm{T}$ vs $1 / \mathrm{T}$ for MS in the presence and absence of CA extract in $1 \mathrm{M} \mathrm{HCl}$. 
Table 4. Activation parameters for MS in presence and absence of CA extract in $1 \mathrm{M} \mathrm{HCl}$.

\begin{tabular}{|c|c|c|c|}
\hline $\begin{array}{l}\text { Conc, } \\
\text { ppm }\end{array}$ & $\begin{array}{l}\mathbf{E}_{\mathrm{a}}^{*} \\
\mathrm{~kJ} \mathrm{~mol}^{-1}\end{array}$ & $\begin{array}{l}\Delta \mathbf{H}^{*} \\
\mathrm{~kJ} \mathrm{~mol}^{-1}\end{array}$ & $\begin{array}{l}-\Delta S^{*} \\
\mathbf{J} \mathbf{m o l}^{-1} \mathbf{K}^{-1}\end{array}$ \\
\hline Blank & 36.2 & 31.6 & 169 \\
\hline 50 & 53.3 & 50.7 & 113 \\
\hline 100 & 53.5 & 51.3 & 114 \\
\hline 150 & 53.1 & 50.3 & 118 \\
\hline 200 & 53.4 & 47.6 & 128 \\
\hline 250 & 52.3 & 48.7 & 125 \\
\hline 300 & 52.2 & 52.2 & 115 \\
\hline
\end{tabular}

\subsection{EFM measurements.}

Figure 6 shows the current-frequency spectral chart obtained from EFM measurements in the absence and presence of various amounts of CA extract. From the chart, we can calculate Maximum peaks that were utilized to measure $\mathrm{i}_{\mathrm{corr}}, \beta_{\mathrm{a}}, \beta_{\mathrm{c}}$, and the causality factors $(\mathrm{CF}-2$ and CF-3), which are listed in Table 5. The given data have shown that $i_{\text {corr }}$ decreases with an increase in CA extract doses, and the \% IE increases by increasing the extract doses. The $\beta_{\mathrm{a}}, \beta_{\mathrm{c}}$ values indicate that the $\mathrm{CA}$ extract has not changed the corrosion mechanism. The values of CF-2 and CF-3 obtained from the chart are close to 2 , and 3 of the theoretical values indicated that the obtained data are of good quality.

From Eq. 11, we can calculate \% IE values, which rise by raising the CA extract doses [19].

$$
\% \text { IE }=100 \times\left[1-\left(i_{\text {corr }} / i^{\circ} \text { corr }\right)\right]
$$

where $\mathrm{i}^{\mathrm{o}}$ corr and $\mathrm{i}_{\text {corr }}$ are current in the absence and presence of CA extract, respectively.
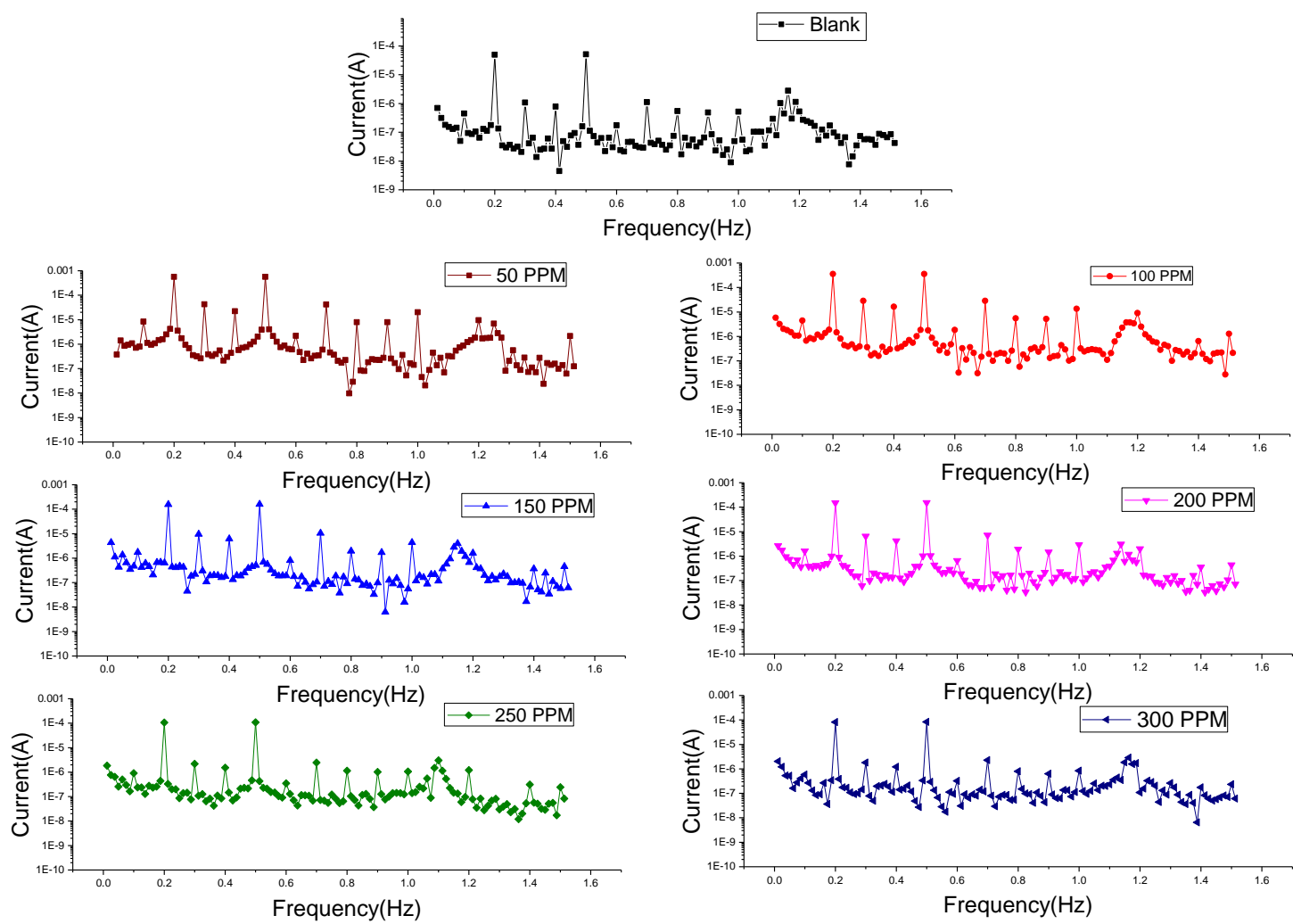

Figure 6. EFM data for MS in the absence and presence of different doses of CA extracts. 
Table 5. EFM data for the corrosion of MS at various doses of CA extract at $25^{\circ} \mathrm{C}$.

\begin{tabular}{|c|c|c|c|c|c|c|c|c|}
\hline $\begin{array}{l}\text { [inh.] } \\
\text { ppm }\end{array}$ & $\begin{array}{l}\mathbf{i}_{\text {corr, }} \\
\mu \mathrm{Acm}^{-2}\end{array}$ & $\begin{array}{l}\beta_{\mathrm{c}}, \\
\mathbf{m V d e c} \\
-1\end{array}$ & $\begin{array}{l}\beta_{\mathrm{a}}, \\
\mathrm{mVdec}^{-1}\end{array}$ & CF-2 & CF-3 & $\begin{array}{l}\text { C.R, } \\
\text { mpy }\end{array}$ & $\boldsymbol{\theta}$ & $\%$ IE \\
\hline 0.0 & 880 & 132.2 & 82.4 & 1.99 & 3.8 & 365.5 & - & - \\
\hline 50 & 424.2 & 124.8 & 77.37 & 1.9 & 3.8 & 217.8 & 0.545 & 54.5 \\
\hline 100 & 283.7 & 152.2 & 95.46 & 1.9 & 2.79 & 117.8 & 0.677 & 67.8 \\
\hline 150 & 259.2 & 131.1 & 96.4 & 1.92 & 3.19 & 107.7 & 0.704 & 70.4 \\
\hline 200 & 191.3 & 126.2 & 108 & 1.80 & 2.60 & 79.47 & 0.783 & 78.3 \\
\hline 250 & 186.1 & 165.4 & 132.1 & 2.0 & 1.9 & 77.31 & 0.789 & 78.9 \\
\hline 300 & 89.26 & 125.9 & 107.6 & 1.68 & 3.48 & 37.08 & 0.899 & 89.9 \\
\hline
\end{tabular}

\subsection{EIS method.}

EIS is a useful method used to study the corrosion of MS in the absence and presence of various doses of CA extract in $1 \mathrm{M} \mathrm{HCl}$. Figs. $(7,8)$ show the Nyquist and Bode curves at the OCP at $25^{\circ} \mathrm{C}$. Nyquist plots are characterized by semicircles loops at low frequencies. This method is represented simply in (Fig. 9) by Randle circuit. This circuit shows a parallel combination of which shows a parallel combination of a charge transfer resistance $\left(\mathrm{R}_{\mathrm{ct}}\right)$ and the double-layer capacitance $\left(\mathrm{C}_{\mathrm{dl}}.\right)$, both in series with solution resistance $\left(\mathrm{R}_{\mathrm{s}}\right)[20]$. The corresponding $\mathrm{R}_{\mathrm{ct}}$ was also utilized to calculate IE and CPE, which is used to describe the double-layer [21]:

$$
\mathrm{C}_{\mathrm{dl}}=\mathrm{Y}_{0}\left(2 \pi \mathrm{f}_{\max }\right)^{\mathrm{n}-1}
$$

With $0 \leq \mathrm{n} \leq 1, \mathrm{j}=\sqrt{-}-1$ and $\mathrm{f}_{\max }$ is the frequency of the highest imaginary value, $Y_{\mathrm{o}}$ is a frequency-independent constant, being defined as pure capacitance for $n=1$, resistance for $n=$ 0 , inductance for $n=-1$. The diffusion process is characterized by the value of $n=0.5$. The value of $(n)$ represents the deviation from the ideal behavior [40]. The values of $n, Y_{o}, R_{c t}$ charge transfer resistance, $\mathrm{C}_{\mathrm{dl}}$ double-layer capacitance, and the IE\% were obtained and listed in (Table 6). The Nyquist plots obtained in the real system represent a general behavior where the double layer on the interface of MS/solution does not behave as an areal capacitor. The data obtained from the equivalent circuit are presented in Table 6 . The data show that $R_{c t}$ values were increased by adding the extract. This is due to the formation of an insulating protective film at the metal/solution interface. Alternatively, $\mathrm{C}_{\mathrm{dl}}$ values were decreased due to a decrease in local dielectric constant and /or to an increase in the thickness of the electrical double layer, suggesting that the inhibitor molecules are adsorbed at the metal/solution interface" [22]. The adsorption of the CA molecules on the MS surface lowered the electrical capacity due to they displace the water molecules, and the CA are originally adsorbed on the surface.

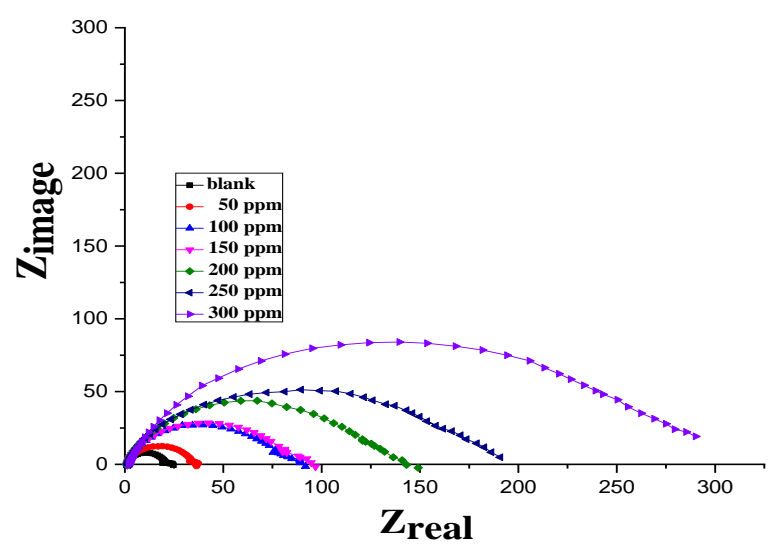

Figure 7. The Nyquist plots for MS in nonexistence and existence of various doses of CA extract at $25^{\circ} \mathrm{C}$. 


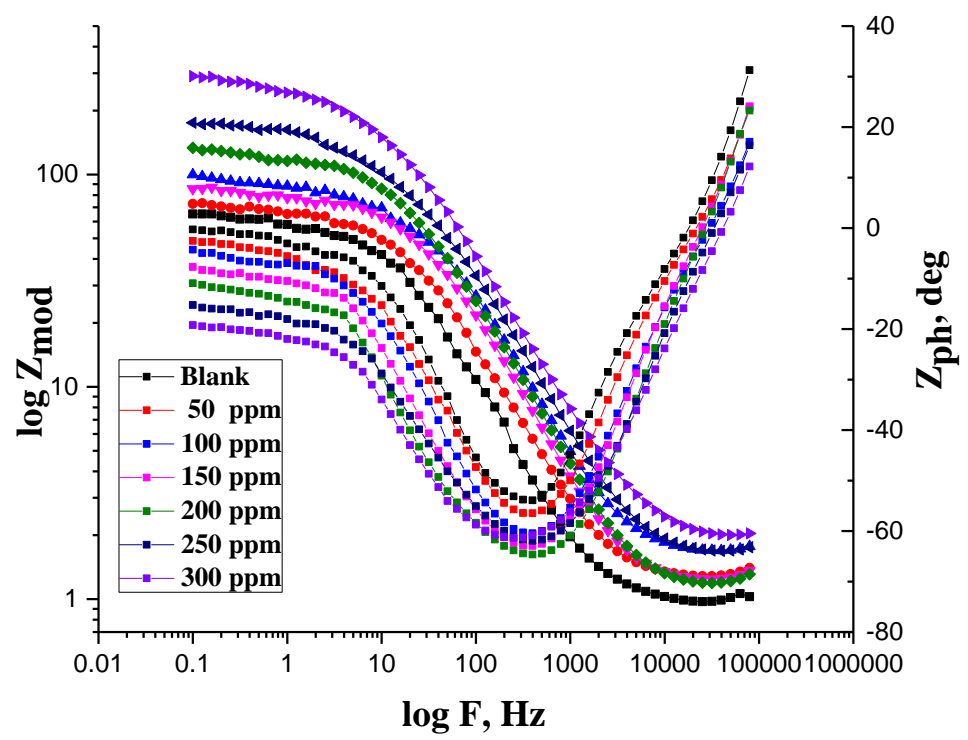

Figure 8. The Bode plots for the dissolution MS in nonexistence and existence of various doses of CA extract in $1 \mathrm{M} \mathrm{HCl}$ at $25^{\circ} \mathrm{C}$.

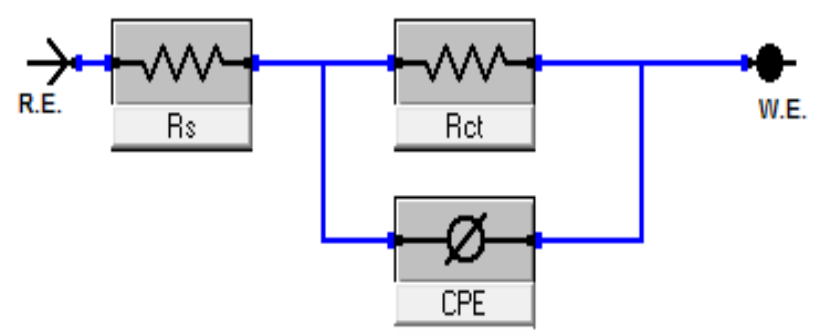

Figure 9. Equivalent circuit utilized to fit the EIS results.

Table 6. EIS value of MS in nonexistence and existence of various doses of CA extract at $25^{\circ} \mathrm{C}$.

\begin{tabular}{|c|c|c|c|c|c|c|}
\hline $\begin{array}{l}\text { [inh.] } \\
\text { ppm }\end{array}$ & $\begin{array}{c}\mathbf{Y}_{0}, \\
\left(\mu \Omega^{-1} \mathrm{~s}^{\mathrm{n}} \mathrm{cm}^{-2}\right) \times 10^{-6}\end{array}$ & $\begin{array}{c}\mathbf{R}_{\mathrm{ct}} \\
\Omega \mathrm{cm}^{-2}\end{array}$ & $\mathbf{n}$ & $\begin{array}{c}\mathrm{C}_{\mathrm{dl}}, \\
\mu \mathrm{Fcm}^{-2}\end{array}$ & $\theta$ & $\%$ IE \\
\hline 0.0 & 279.9 & 19.41 & 0.894 & 151 & - & - \\
\hline 50 & 204.9 & 62.15 & 0.875 & 100 & 0.687 & 68.7 \\
\hline 100 & 191.5 & 74.52 & 0.852 & 91 & 0.739 & 73.9 \\
\hline 150 & 171.5 & 76.84 & 0.858 & 84 & 0.747 & 74.7 \\
\hline 200 & 156.6 & 113.9 & 0.851 & 77 & 0.822 & 82.2 \\
\hline 250 & 155.2 & 144.6 & 0.811 & 64 & 0.866 & 86.6 \\
\hline 300 & 146.8 & 247.6 & 0.789 & 61 & 0.922 & 92.2 \\
\hline
\end{tabular}

\subsection{PP tests.}

PP measurements were carried out to study the effect of CA extract on the anodic and cathodic reactions occurring in the system. Figure 10 demonstrates the potentiodynamic polarization curves for mild steel without and with various doses of CA extract at $25^{\circ} \mathrm{C}$.

The outcome electrochemical parameters are cathodic $\left(\beta_{\mathrm{c}}\right)$ and anodic $\left(\beta_{\mathrm{a}}\right)$ Tafel slopes, corrosion potential $\left(\mathrm{E}_{\mathrm{corr}}\right.$ ), and corrosion current density ( $\left.\mathrm{i}_{\mathrm{corr}}\right)$, which acquired and recorded in Table 7 [23]. From the outcoming data, we noted that (icorr) decrease with increasing of CA extract doses, but the $\left(\beta_{\mathrm{a}}, \beta_{\mathrm{c}}\right)$ are approximately constant, and parallelled to the retardation of the 2 reactions were influence without exchanging the liquefaction mechanism [24]. Figure 10 showed that both cathodic and anodic reactions are inhibited, which indicated that CA extract is a mixed type inhibitor [25]. The appending of CA extract are exchange the Ecorr data in a negative direction. The (\%IE) calculated from $\mathrm{i}_{\text {corr }}$ reveals that the presence of various 
concentrations of CA extract decreases the anodic and cathodic current densities and the polarization resistance.

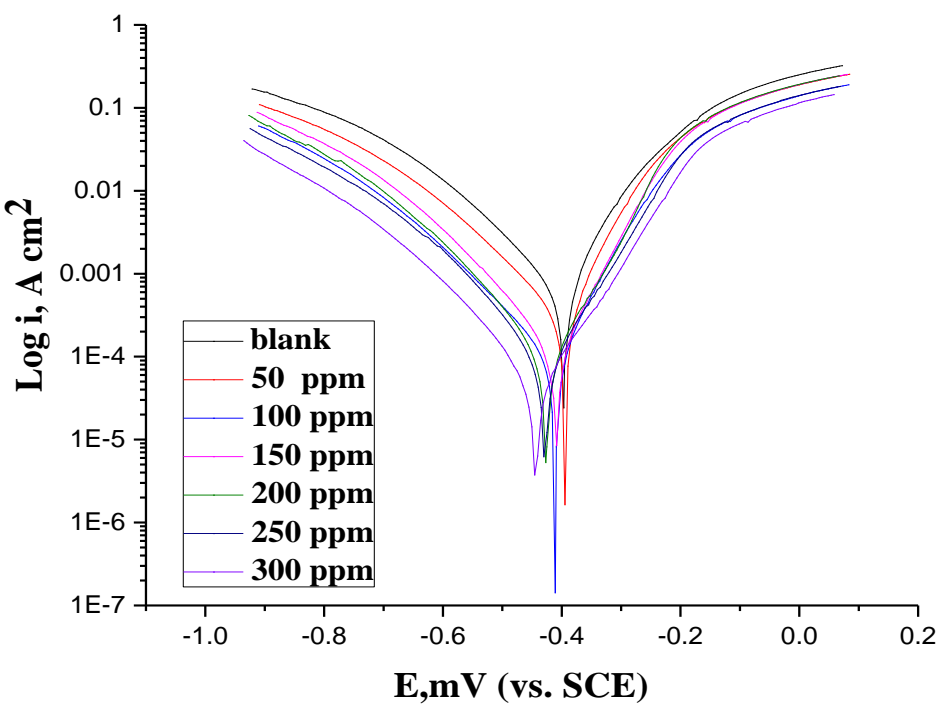

Figure 10. PP plots for the dissolution of MS in the presence and absence of various doses of CA extract.

Table 7. PP parameters of MS, including various doses of CA extract.

\begin{tabular}{|c|c|c|c|c|c|c|c|c|}
\hline $\begin{array}{l}\text { [inh.] } \\
\text { ppm }\end{array}$ & $\begin{array}{l}\text { - Ecorr, } \\
\text { (mV vs.SCE) }\end{array}$ & $\begin{array}{l}\mathbf{R}_{\mathbf{p}} \\
\mathbf{\Omega}\end{array}$ & $\begin{array}{l}\mathbf{i}_{\text {corr, }} \\
\mu \mathrm{A} \mathbf{c m}^{-2}\end{array}$ & $\begin{array}{l}\beta_{c} \\
\text { mV } \operatorname{dec}^{-1}\end{array}$ & $\begin{array}{l}\beta_{\mathrm{a}} \\
\mathrm{mV} \operatorname{dec}^{-1}\end{array}$ & $\begin{array}{l}\text { C.R, } \\
\text { mpy }\end{array}$ & $\boldsymbol{\theta}$ & $\%$ IE \\
\hline 0 & 304 & 33 & 778 & 167 & 95 & 303 & - & - \\
\hline 50 & 395 & 66 & 356 & 150 & 84 & 148 & 0.542 & 54.2 \\
\hline 100 & 411 & 146 & 157 & 149 & 82 & 65 & 0.798 & 79.8 \\
\hline 150 & 415 & 166 & 135 & 137 & 83 & 57 & 0.826 & 82.6 \\
\hline 200 & 426 & 211 & 115 & 136 & 95 & 48 & 0.852 & 85.2 \\
\hline 250 & 428 & 221 & 98 & 126 & 83 & 41 & 0.874 & 87.4 \\
\hline 300 & 444 & 346 & 56 & 115 & 73 & 25 & 0.928 & 92.8 \\
\hline
\end{tabular}

3.5. Surface characterization.

3.5.1. AFM study.

AFM is a useful method used to study the morphology of the MS surface. (Figs. 11-13) are 3D images for $\mathrm{M}-\mathrm{S}$ polished surface in absence and presence of CA extract (300ppm) in $1 \mathrm{M}$ $\mathrm{HCl}$ for 24 hour at $25^{\circ} \mathrm{C}[26]$. From the figures, we can see that: The surface is very clear for the free surface in the absence of $\mathrm{CA}$ extract and $\mathrm{HCl}$, and the average roughness is $14.1 \mathrm{~nm}$ Figure (11); The surface more corroded in the absence of CA extract at $1 \mathrm{M} \mathrm{HCl}$, and the average roughness is $392.58 \mathrm{~nm}$ Figure (12); The surface is less corroded in the presence of CA extract (300 ppm), and the average roughness is $212.9 \mathrm{~nm}$ Figure (13).

From the figures, we understand that: the roughness reduced in the presence of the inhibitor due to the formation of a protective film of CA extract on MS surface [27].

\subsubsection{ATR-FTIR analysis.}

In this method, we identify the adsorbed functional groups of CA extract adsorbed on the MS surface. "The mechanism of inhibition of corrosion of M-S by CA extract in $\mathrm{HCl}$ can be illustrated on the basis of molecular adsorption [28]. Chemical bonds in a molecule had been recognized by generating an infrared absorption spectrum. Functional groups and 
characterizing covalent bonding information had been detected by FT-IR, which is an influential analytical device [29].
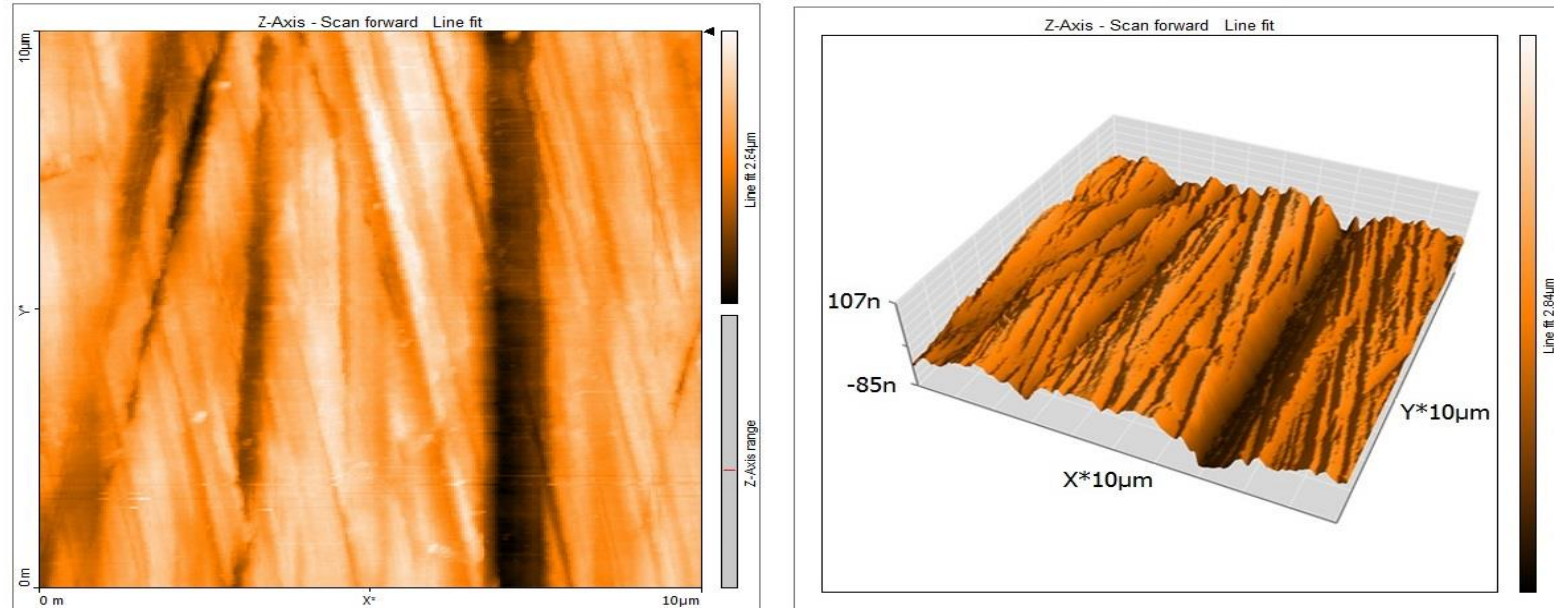

Figure 11. AFM 2D (a) and 3D (b) of MS free surface.
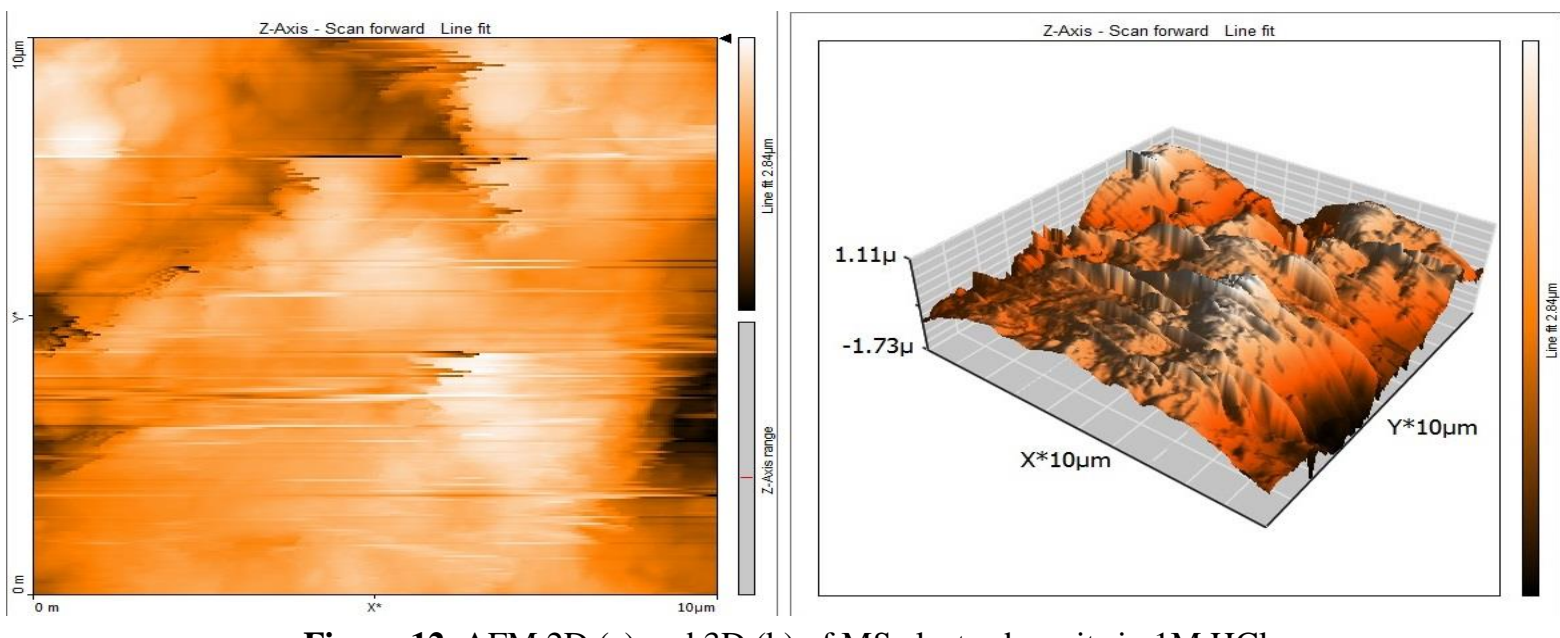

Figure 12. AFM 2D (a) and 3D (b) of MS electrodeposits in $1 \mathrm{M} \mathrm{HCl.}$
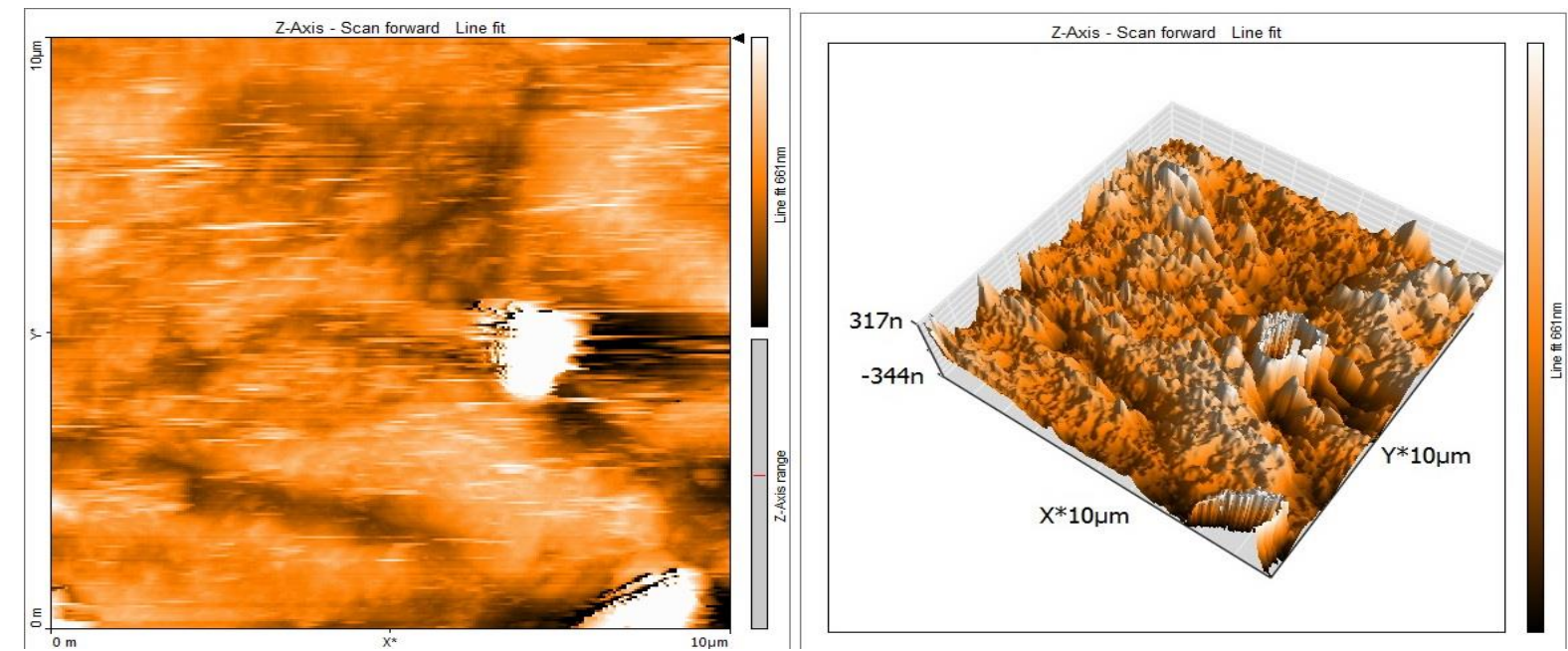

Figure 13. AFM images 2D (a) and 3D (b) of MS electrodeposits in the presence of CA extract.

Figure (14) signifies the ATR-IR spectrum of CA extract and the construction of the adsorbed film over the MS surface after immersion for $6 \mathrm{hr}$ in $1 \mathrm{M} \mathrm{HCl}$. FT-IR spectra of the CA extract stock $(1000 \mathrm{ppm})$ and the spectra of MS surface after immersion in $1 \mathrm{M} \mathrm{HCl}+300$ ppm of CA extract for 6 hours as compared to each other. From the compared spectra, we note that there are small shifts on the peak of some function groups, the absence of some functional 
group, and some peaks not changed. These spectra are characteristic by $\mathrm{OH}^{-}$group $(3317 \mathrm{~cm}-1-$ $3618 \mathrm{~cm}^{-1)}$ and carboxylate group at $1600 \mathrm{~cm}^{-1}$. These shifts indicate that there is an interaction between MS and some of the inhibitor's molecules". The corrosion of MS inhibited after the addition of CA extract.

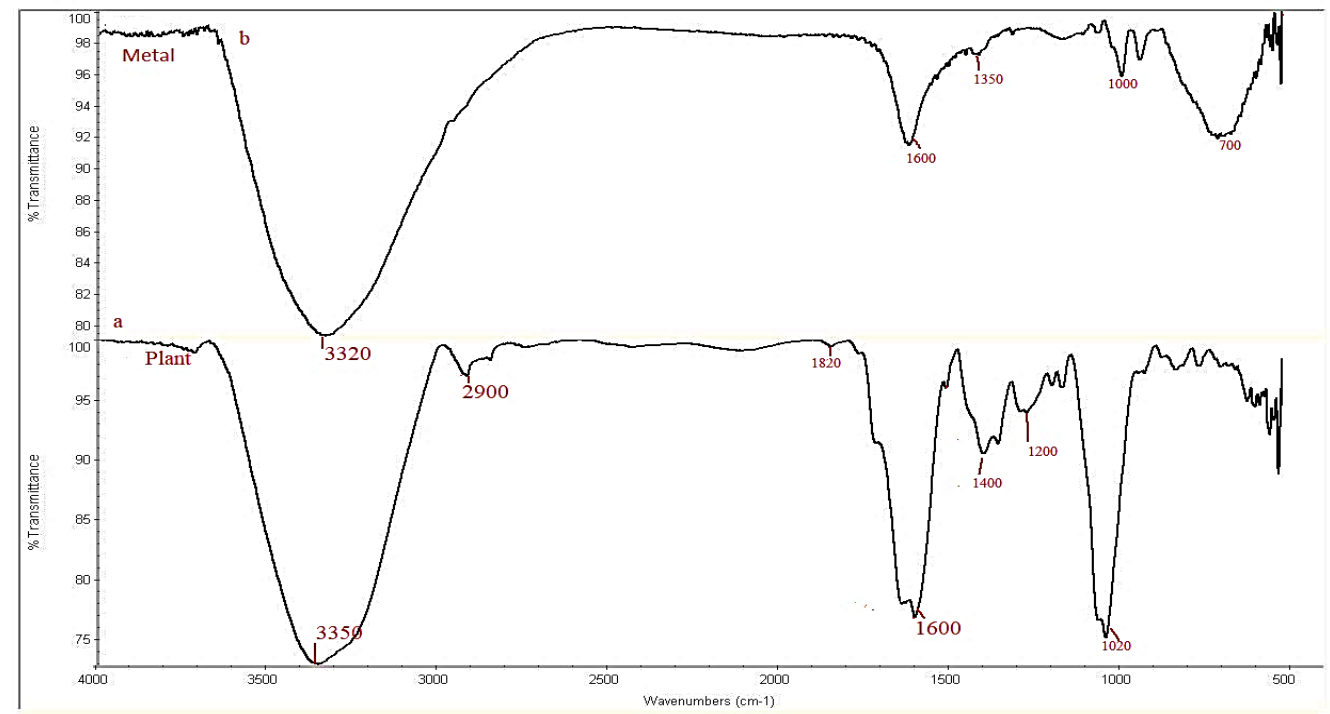

Figure 14. ATR- FTIR spectra of CA stock solution (1000 ppm)(a) and adsorbed layer of CA on MS surface(b).

\subsubsection{XPS.}

X-ray photoelectron spectroscopy (XPS) analysis was performed to confirm the adsorption of the studied CA on the "MS surface and determine the chemical nature of the inhibitors/steel interface, and the results were discussed as below. The high-resolution XPS spectra survey obtained for M-S surface corroded in $0.1 \mathrm{M} \mathrm{HCl}$ solution in the presence of CA molecule is illustrated in Fig.15. All XPS spectra show complex forms, which were assigned to the corresponding species through a deconvolution fitting procedure. The binding energies $(\mathrm{BE}, \mathrm{eV})$ and the corresponding quantification (\%) of each peak component are listed in Table 8. The high-resolution XPS spectra obtained for MS surface corroded in $0.1 \mathrm{M} \mathrm{HCl}$ composed of ( $\mathrm{Fe} \mathrm{2p,} \mathrm{O} \mathrm{1s,} \mathrm{Cl} \mathrm{2p,} \mathrm{C} \mathrm{1s)} \mathrm{as} \mathrm{illustrated} \mathrm{in} \mathrm{Fig.16.} \mathrm{While} \mathrm{in} \mathrm{the} \mathrm{presence} \mathrm{of} \mathrm{the} \mathrm{studied} \mathrm{CA}$ inhibitor, the XPS spectra consist of the same elements (Fe 2p, O 1s, Cl 2p, C 1s) in addition to $\mathrm{N} 1 \mathrm{~s}$ core level, as shown in Fig. 17. The XPS spectrum of Fe $2 \mathrm{p}$ shows six peaks. The high peak at lower binding energy $(711.2 \mathrm{eV})$ corresponds to metallic iron [30]. The peak located at $714.6 \mathrm{eV}$ is attributable to $\mathrm{Fe} 2 \mathrm{p} 3 / 2$, and the small peak at $719.40 \mathrm{eV}$ corresponds to the satellite of $\mathrm{Fe}^{3+}$. In addition, the peaks at $724.3 \mathrm{eV}$ and $727.9 \mathrm{eV}$ can be attributed to $\mathrm{Fe} 2 \mathrm{p} 1 / 2$ due to the presence of iron in the form of $\mathrm{Fe}_{3} \mathrm{O}_{4}, \alpha-\mathrm{Fe}_{2} \mathrm{O}_{3}$, and $\mathrm{FeOOH}$ [31]. The last peak at 732.4 $\mathrm{eV}$, which is related to the oxidation of the steel surface. The $\mathrm{C} 1 \mathrm{~s}$ spectra of $\mathrm{M}-\mathrm{S}$ in $\mathrm{HCl}$ alone and with the CA show two characteristic peaks at binding energy $284.6 \mathrm{eV}$ and $286.2 \mathrm{eV}$ assigned to a $\mathrm{C}-\mathrm{C}$ bond and $\mathrm{C}=\mathrm{O}$ bond, respectively, while in the case of $\mathrm{CA}$ only, there is more peak observed at $288.4 \mathrm{eV}$ which is attributed to the $\mathrm{sp}^{2}$-hybridized carbon, which comes from the inhibitor molecule. The XPS spectra of $\mathrm{O} 1 \mathrm{~s}$ in blank solution shows three peaks, one of them at $\mathrm{BE} 530.0 \mathrm{eV}$, which is attributed to the $\mathrm{Fe}$ oxide $\left(\mathrm{FeO}\right.$ and $\left.\mathrm{Fe}_{2} \mathrm{O}_{3}\right)$ [32]. The second one at a binding energy of $399.9 \mathrm{eV}$, this peak could be attributed to the neutral imine $(-\mathrm{N}=)$, and amine (-N-H) nitrogen atoms as previously reported [33]. According to the XPS results, the appearance peak of $\mathrm{N}$ in the protected sample surface spectra confirm adsorption of the studied CA inhibitor at the sample surface. Moreover, in the presence of the investigated 
inhibitors", it is clear that the O1s core level signal is significantly decreased, which is consistent with the adsorption of the CA on the M-S surface. All that confirms the adsorption of the investigated inhibitors on the MS surface in the $\mathrm{HCl}$ solution.

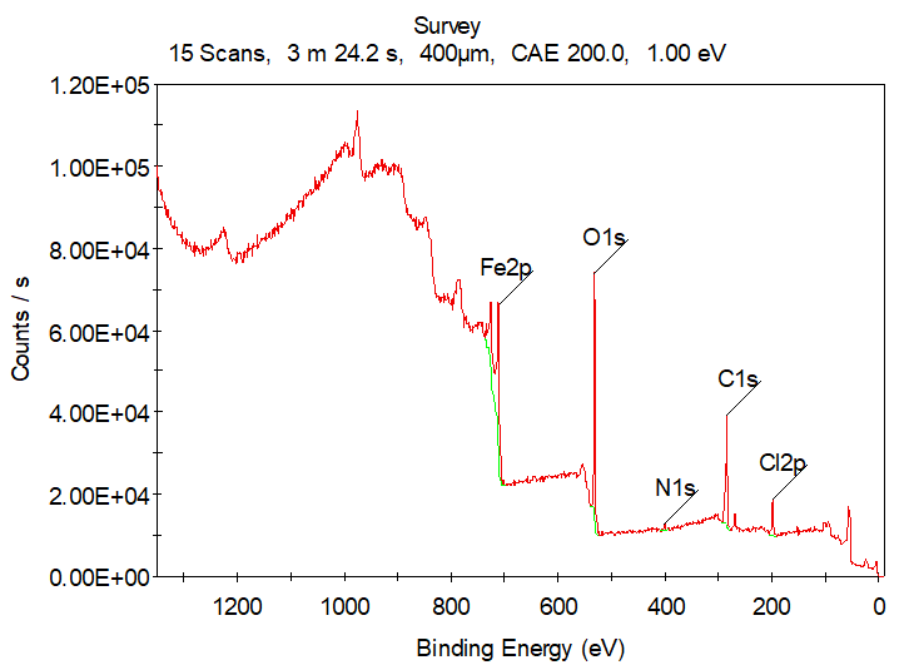

Figure 15. The XPS survey spectrum results of CA extract adsorbed on the $\mathrm{MS}$ in $1 \mathrm{M} \mathrm{HCl}$ at $25^{\circ} \mathrm{C}$.

Table. 8. The binding energies (BE, eV) and the corresponding quantification (\%) For CA extract.

\begin{tabular}{l|l|l|l|l} 
CA extract & Peak BE & FWHM eV & Area (P) CPS.eV & Atomic \% \\
\hline O1s & 531.32 & 3.61 & 236337 & 40.37 \\
\hline Fe2p & 711.43 & 4.77 & 352512.4 & 12.18 \\
\hline C1s & 285.11 & 3 & 90437.76 & 39.44 \\
\hline C12p & 199.2 & 3.58 & 35415.26 & 6.49 \\
\hline N1s & 401.05 & 3.34 & 5913.11 & 1.52
\end{tabular}
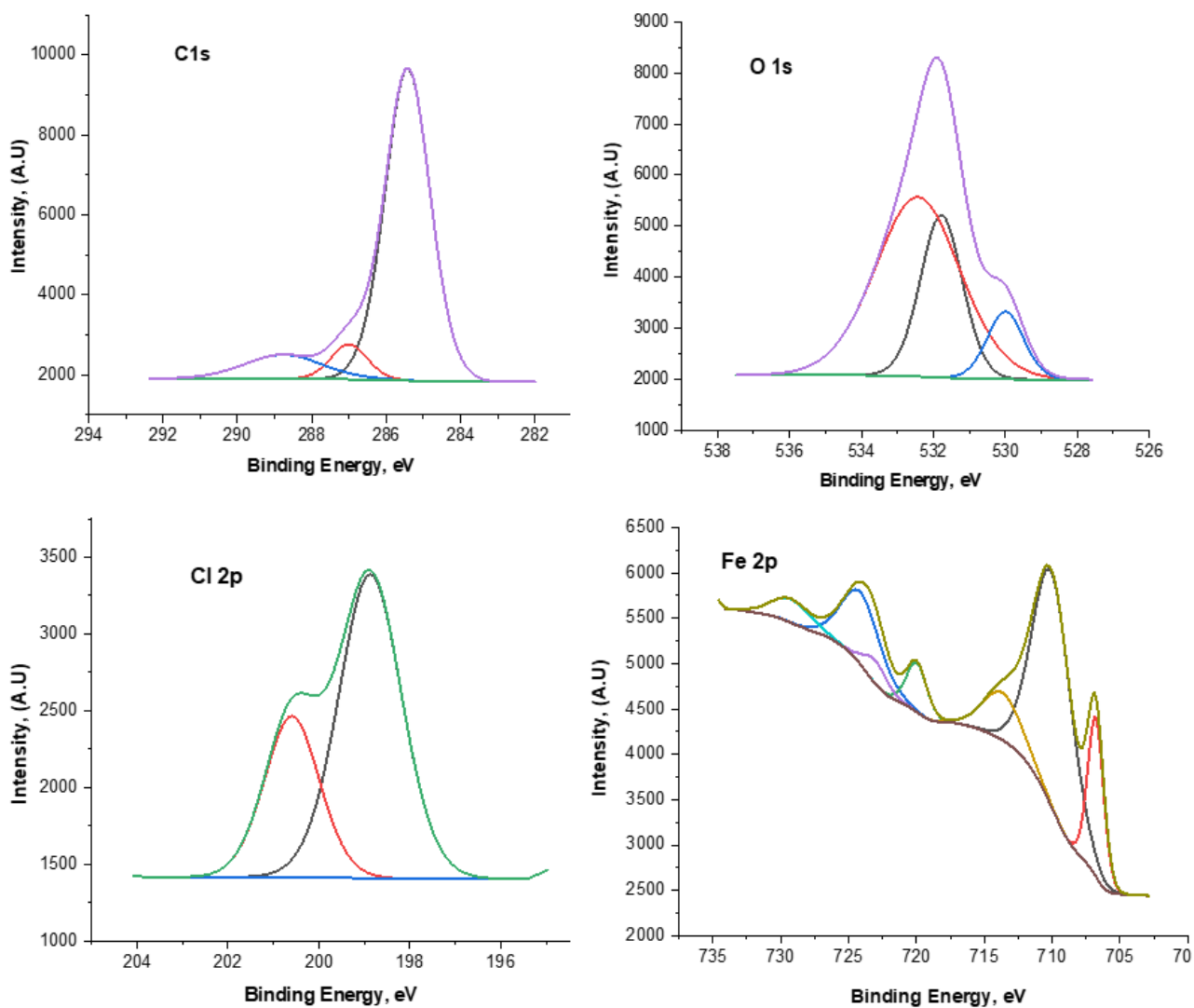

Figure 16. High-resolution X-ray photoelectron deconvoluted profiles of (a) C 1s, (b) O 1s, (c) $\mathrm{Cl} 2 \mathrm{p}$, and (d) Fe $2 \mathrm{p}$ for $\mathrm{MS}$ in $1 \mathrm{M} \mathrm{HCl}$. 

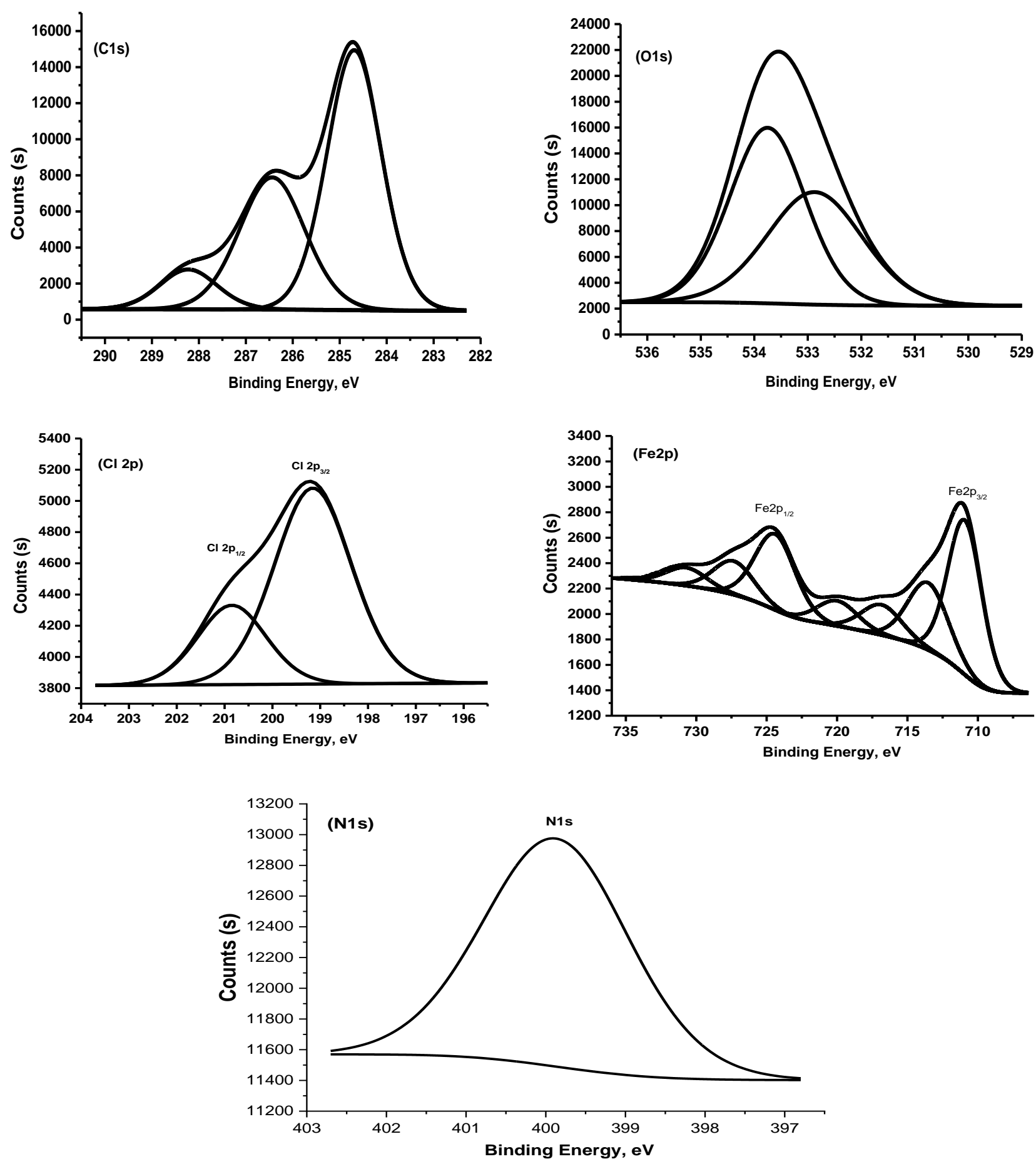

Figure 17. High-resolution X-ray photoelectron deconvoluted profiles of (a) C 1s, (b) O 1s, (c) Cl 2p, (d) Fe 2p, and (e) $\mathrm{N}$ 1s for $\mathrm{MS}$ in $0.1 \mathrm{M} \mathrm{HCl}+\mathrm{CA}$ extract.

\subsection{Mechanism of corrosion inhibition.}

According to weight loss and electrochemical measurements, "the additions of CA extract leads to decrease the corrosion of MS. The outcome data showed that the mechanism of inhibition depends on the blocking of active sites of the MS surface by adsorption of CA extract. The adsorption of CA extract is carried by the adsorption of heteroatoms of the inhibitor, which are in different constituents of extract besides the availability of $\pi$ - electrons in the aromatic system [34]. By phytochemical analysis, we know that: the CA extract many organic compounds. Temperatures study results showed that mechanical adsorption happens through physical adsorption. The MS surface, with its positive charge, prefers the adsorption 
of $\mathrm{Cl}^{-}$to produce a negative charge surface". These molecules (CA extract) will be existing in the protonated form, so it can adsorb directly on the negative surface of MS [35] in an acidic medium by electrostatic attraction, as shown below. Schematic representation of the mode of adsorption of extract molecules on MS surface is shown in Fig. 18.

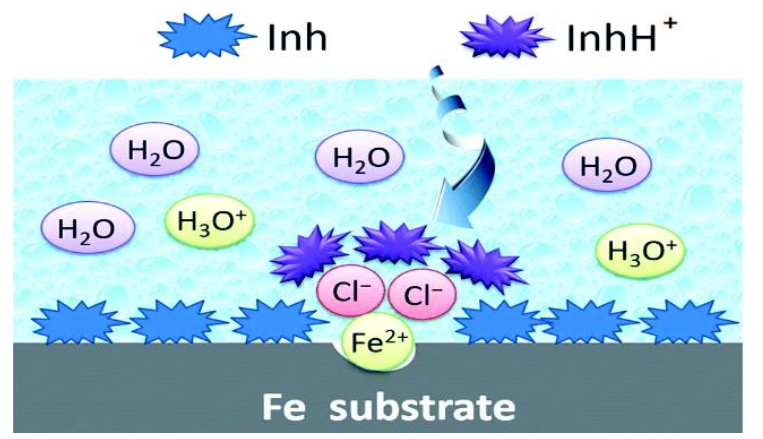

Figure 18. Schematic representation of the mechanism of inhibition.

\section{Conclusions}

The conclusions below are given according to the above results: CA extract is a good inhibitor used to decrease the corrosion of MS in $\mathrm{HCl}$ solutions; The outcomes data explained that: the inhibition efficiency increase by increasing the concentration of CA extract; When the plant extract is added, the double-layer, capacitances reduce, and charge travel resistance rises regardless of the blank solution; The adsorption of CA extract follows Langmuir adsorption isotherm; The result explained that the CA extract acts as a mixed-kind inhibitor; Techniques that are used to detect the corrosion inhibition process are MR, PP, EFM, and EIS are in reasonably good agreement; There is good agreement between chemical and electrochemical techniques.

\section{Funding}

This research received no external funding.

\section{Acknowledgments}

All our gratitude to the anonymous referees for their careful reading of the manuscript and valuable comments which helped in shaping this paper to the present form. We thank all laboratory staff of corrosion chemistry from the University of Mansoura (Egypt) for their kind cooperation.

\section{Conflicts of Interest}

The authors declare no conflict of interest.

\section{References}

1. Verma, C.; Quraishi M.A.; Ebenso E.E. Microwave and ultrasound irradiations for the synthesis of environmentally sustainable corrosion inhibitors: An overview. Sustainable Chemistry and Pharmacy 2018, 10, 134-147, https://doi.org/10.1016/j.scp.2018.11.001.

2. Shetty, S.D.; Shetty, P.; Nayak, H.V.S. The inhibition action of N-(furfuryl)-N'-phenyl thiourea on the corrosion of mild stell in acid media. J. Serb. Chem. Soc. 2006, 71, 1073-1082, https://doi.org/10.1016/j.matlet.2006.09.009. 
3. Aoun, S.B.; Messali, M. Microwave-assisted synthesis of green inhibitor for carbon steel acid corrosion. Int. J. Electrochem. Sci. 2018, 13, 3757-3776, https://doi.org/10.20964/2018.04.55.

4. Popoola, L.T. Progress on pharmaceutical drugs, plant extracts and ionic liquids as corrosion inhibitors. Heliyon. 2019, 5, https://doi.org/10.1016/j.heliyon.2019.e01143.

5. Verma, C.; Ebenso, E.E.; Bahadur, I.; Quraishi, M. An overview on plant extracts as environmentally sustainable and green corrosion inhibitors for metals and alloys in aggressive corrosive media. J. Mol. Liq. 2018b, 266, 577-590, https://doi.org/10.1016/j.molliq.2018.06.110.

6. Castilho, P; Liu, K.; Rodrigues, A.I.; Feio, S.; Tomi, F.; Casanova, J. Composition and antimicrobial activity of the essential oil of Clinopodium ascendens (Jordan) Sampaio from Madeira. Flavour Fragr. J. 2007, 22, 139-144, https://doi.org/10.1002/ffj.1771.

7. Bennacer, A.; Cherif, H.S. Contribution to the Ethnobotanical, Phytochemical, Antimicrobial and Antioxidant Study of the Leaves' Aqueous Extract of the Common Walnut "Juglans regia L.". International Journal of Pharmacology, Phytochemistry and Ethnomedicine 2017, 7, 41-52, https://doi.org/10.18052/www.scipress.com/IJPPE.7.41.

8. Fouda, A.S.; El-Awady, G.Y.; El Behairy, W.T. Prosopis juliflora Plant Extract as Potential Corrosion Inhibitor for Low-Carbon Steel in $1 \mathrm{M} \mathrm{HCl} \mathrm{Solution.} \mathrm{Journal} \mathrm{of} \mathrm{Bio-} \mathrm{and} \mathrm{Tribo-Corrosion} \mathrm{2017,} \mathrm{4,}$ https://doi.org/10.1007/s40735-017-0124-X.

9. Shainy, K.M.; Rugmini Ammal, P.; Unni, K.N.; Benjamin, S.; Joseph, A. Surface Interaction and Corrosion Inhibition of Mild Steel in Hydrochloric Acid Using Pyoverdine, an Eco-Friendly Biomolecule. Journal of Bio- and Tribo-Corrosion 2016, 2, https://doi.org/10.1007/s40735-016-0050-3.

10. Elabbasy, H.M.; Zidan, S.M.; Fouda, A.S. Inhibitive behavior of ambrosia maritima extract as aneco-friendly corrosion inhibitor for carbon steel in $1 \mathrm{M} \mathrm{HCl}$. Zastita Materijala 2019, 60, 129-146, https://doi.org/10.5937/zasmat1902129E.

11. Khadraoui, A.; Khelifa, A.; Hamitouche, H.; Mehdaoui, R. Inhibitive effect by extract of Mentha rotundifolia leaves on the corrosion of steel in $1 \mathrm{M} \mathrm{HCl}$ solution. Research on Chemical Intermediates 2014, 40, 961972, https://doi.org/10.1007/s11164-012-1014-y.

12. Fouda, A.S.; Abousalem, A.S.; El-Ewady, G.Y. Mitigation of corrosion of carbon steel in acidic solutions using an aqueous extract of Tilia cordata as green corrosion inhibitor. International Journal of Industrial Chemistry 2017, 8, 61-73, https://doi.org/10.1007/s40090-016-0102-z.

13. Okafor, P.C.; Ikpi, M.E.; Uwah, I.E.; Ebenso, E.E.; Ekpe, U.J.; Umoren, S.A. Inhibitory action of Phyllanthus amarus extracts on the corrosion of mild steel in acidic media. Corrosion Science 2008, 50, 2310-2317, https://doi.org/10.1016/j.corsci.2008.05.009.

14. Raghavendra, N.; Hublikar, L.V.; Patil, S.M.; Ganiger, P.J.; Bhinge, A.S. Efficiency of sapota leaf extract against aluminium corrosion in a $3 \mathrm{M}$ sodium hydroxide hostile fluid atmosphere: a green and sustainable approach. Bulletin of Materials Science 2019, 42, https://doi.org/10.1007/s12034-019-1922-1.

15. Fouda, A.S.; Abd El-Maksoud, S.A.; El-Hossiany, A.; Ibrahim, A. Corrosion Protection of Stainless Steel 201 in Acidic Media using Novel Hydrazine Derivatives as Corrosion Inhibitors. Int. J. Electrochem. Sci. 2019, 14, 2187-2207, https://doi.org/10.20964/2019.03.15.

16. Boumhara, K.; Harhar, H.; Tabyaoui, M.; Bellaouchou, A.; Guenbour, A.; Zarrouk, A. Corrosion Inhibition of Mild Steel in 0.5 M H2SO4 Solution by Artemisia herba-alba Oil. Journal of Bio- and Tribo-Corrosion 2018, 5, https://doi.org/10.1007/s40735-018-0202-8.

17. Fouda, A.S.; Rashwan, S.; Kamel, M.M.; Arman, N.M. Adsorption and Inhibition Behavior of Avicennia Marina for Zn Metal in Hydrochloric Acid Solution. International Journal of Electrochemical Science 2017, 12, 11789-11804, https://doi.org/10.20964/2017.12.95.

18. Fouda, A.S.; Abdel Azeem, M.; Mohamed, S.A., El-Hossiany, A.; El-Desouky, E. Corrosion Inhibition and Adsorption Behavior of Nerium Oleander Extract on Carbon Steel in Hydrochloric Acid Solution. Int. J. Electrochem. Sci. 2019, 14, 3932 - 3948, https://doi.org/10.20964/2019.04.44.

19. Fouda, A.S.; Rashwan, S.; El-Hossiany, A.; El-Morsy, F.E. Corrosion Inhibition of Zinc in Hydrochloric Acid Solution using some organic compounds as Eco-friendly Inhibitors. JCBPS. 2019, 9, 001-024, https://doi.org/10.24214/jcbps.A.9.1.00124.

20. Fouda, A.S.; Abd El-Maksoud, S.A.; El-Hossiany, A.; Ibrahim, A. Effectiveness of Some Organic Compounds as Corrosion Inhibitors for Stainless Steel 201 in $1 \mathrm{M} \mathrm{HCl}$ : Experimental and Theoretical Studies. Int. J. Electrochem. Sci. 2018, 13, 9826 - 9846, https://doi.org/10.20964/2018.10.36.

21. Appa Rao, B.V.; Narsihma Reddy, M. Formation, characterization and corrosion protection efficiency of self-assembled 1-octadecyl-1H-imidazole films on copper for corrosion protection. Arabian Journal of Chemistry 2017, 10, S3270-S3283, https://doi.org/10.1016/j.arabjc.2013.12.026.

22. Wasim, M.; Shoaib, S.; Mubarak, N.M.; Inamuddin; Asiri, A.M. Factors influencing corrosion of metal pipes in soils. Environmental Chemistry Letters 2018, 16, 861-879, https://doi.org/10.1007/s10311-018-0731-x.

23. Soltani, N.; Tavakkoli, N.; Attaran, A.; Karimi, B.; Khayatkashani, M. Inhibitory effect of Pistacia khinjuk aerial part extract for carbon steel corrosion in sulfuric acid and hydrochloric acid solutions. Chemical Papers 2020, 74, 1799-1815, https://doi.org/10.1007/s11696-019-01026-y. 
24. Fouda, A.S.; Abd El-Maksoud, S.A.; El-Hossiany, A.; Ibrahim, A. Evolution of the Corrosion-inhibiting Efficiency of Novel Hydrazine Derivatives against Corrosion of Stainless Steel 201 in Acidic Medium. Int. J. Electrochem. Sci. 2019, 14, 6045-6064, https://doi.org/10.20964/2019.07.65.

25. Fouda, A.S.; Killa, H.M.; Farouk, A.; Salem, A.M. CalicotomeExtract as a Friendly Corrosion Inhibitor forCarbon Steel in Polluted NaClSolution: Chemical and Electrochemical Studies. Egyptian Journal of Chemistry 2019, 62, 1879-1894, https://doi.org/10.21608/EJCHEM.2019.7656.1649.

26. Fouda, A.S.; Eissa, M.; El-Hossiany, A. Ciprofloxacin as Eco-Friendly Corrosion Inhibitor for Carbon Steel in Hydrochloric Acid Solution. Int. J. Electrochem. Sci. 2018, 13, 11096-11112, https://doi.org/10.20964/2018.11.86.

27. Fouda, A.S.; Abdel Haleem, E. Berry Leaves Extract as Green Effective Corrosion Inhibitor for Cu in Nitric Acid Solutions. Surface Engineering and Applied Electrochemistry 2018, 54, 498-507, https://doi.org/10.3103/S1068375518050034.

28. Hsissou, R.; Abbout, S.; Berisha, A.; Berradi, M.; Assouag, M.; Hajjaji, N.; Elharfi, A. Experimental, DFT and molecular dynamics simulation on the inhibition performance of the DGDCBA epoxy polymer against the corrosion of the E24 carbon steel in $1.0 \mathrm{M} \mathrm{HCl}$ solution. Journal of Molecular Structure 2019, 1182 , 340-351, https://doi.org/10.1016/j.molstruc.2018.12.030.

29. Fouda, A.S.; El-Ewady, G.; Ali, A.H. Modazar as promising corrosion inhibitor of carbon steel in hydrochloric acid solution. Green Chemistry Letters and Reviews 2017, 10, 88-100, https://doi.org/10.1080/17518253.2017.1299228.

30. Motawea, M. M.; El-Hossiany, A.; Fouda, A.S. Corrosion Control of Copper in Nitric Acid Solution using Chenopodium Extract. Int. J. Electrochem. Sci. 2019, 14, 1372-1387, https://doi.org/10.20964/2019.02.29.

31. Fouda, A.S.; Zaki, E.G.; Khalifa, M.M.A. Some New Nonionic Surfactants Based on Propane Tricarboxylic Acid as Corrosion Inhibitors for Low Carbon Steel in Hydrochloric Acid Solutions. Journal of Bio- and Tribo-Corrosion 2019, 5, https://doi.org/10.1007/s40735-019-0223-y.

32. Habibiyan, A.; Ramezanzadeh, B.; Mahdavian, M.; Kasaeian, M. Facile size and chemistry-controlled synthesis of mussel-inspired biopolymers based on Polydopamine Nanospheres: Application as eco-friendly corrosion inhibitors for mild steel against aqueous acidic solution. Journal of Molecular Liquids 2020, 298, https://doi.org/10.1016/j.molliq.2019.111974.

33. Zhang, S.; Hou, L.; Du, H.; Wei, H.; Liu, B.; Wei, Y. A study on the interaction between chloride ions and $\mathrm{CO} 2$ towards carbon steel corrosion. Corrosion Science 2020, 167, https://doi.org/10.1016/j.corsci.2020.108531.

34. Baymou, Y.; Bidi, H.; Ebn Touhami, M.; Allam, M.; Rkayae, M.; Belakhmima, R.A. Corrosion Protection for Cast Iron in Sulfamic Acid Solutions and Studies of the Cooperative Effect Between Cationic Surfactant and Acid Counterions. Journal of Bio- and Tribo-Corrosion 2018, 4, https://doi.org/10.1007/s40735-0180127-2.

35. Fouda A.S., Rashwan S.M., Kamel M.M., Abdel Haleem E., Chemical, electrochemical and surface morphology investigation of Cichorium intybus extract (CIE) as beneficial inhibitor for $\mathrm{Al}$ in $2 \mathrm{M} \mathrm{HCl}$ acid, Letters in Applied Nano Bio Science 2020, 9, 1064-1073. 